\title{
Creativity and the Age-Old Resistance to Change Problem in RE
}

\author{
Gil Regev ${ }^{1}$, Donald C. Gause ${ }^{2}$, Alain Wegmann ${ }^{1}$ \\ ${ }^{1}$ Ecole Polytechnique Fédérale de Lausanne (EPFL), School of Computer and Communication \\ Sciences, CH-1015 Lausanne, Switzerland, \{gil.regev, alain.wegmann\}@epfl.ch \\ ${ }^{2}$ State University of New York at Binghamton and Savile Row, LLC, U.S.A \\ dgause@binghamton.edu
}

\begin{abstract}
Creativity is about bringing unforeseen change to habitual ways of doing things. Understanding the challenges of introducing innovation in organizations is, therefore, essential during the requirements phase of today's computer systems design projects. However, there are many legitimate obstacles to creativity. To explain some of them, we explore creativity in terms of change to norms that are well accepted in an organization. These norms are grounded in the worldview of the organization. Creativity is therefore constrained by the amount of change that can be made to norms and worldview. We describe some of the mechanisms that work in favor and against change and offer suggestions on how to make better use of these mechanisms in introducing currently accepted and recently developed $R E$ methodologies into mainstream commercial systems design approaches.
\end{abstract}

\section{Introduction}

Creativity in $\mathrm{RE}$ is about the invention of novel and appropriate requirements [12]. Creativity is central to RE, see for example [6]. More recently, it has received renewed interest with conceptual frameworks and field studies $[3,9,12]$. For one thing, the mere act of introducing $\mathrm{RE}$, at all, let alone new RE methodologies into historically successful product design organizations, involves the introduction of change to already proven processes. For another thing, we now know how to incorporate creativity into the very RE process to yield new, innovative product features and functions. However, creativity techniques are not integrated in most RE research and commercial methods.

Creative requirements need to durably influence the behavior of an organization and therefore need to be accepted by it. In this paper we discuss creativity as the tension between the need for change and the need for stability of an organization. We therefore explore the forces that favor creativity and those that place barriers against it. We show that change, and even more so creative change, is often perceived as a menace to established order and, as such, is difficult to accept by the target community. Ironically enough, this is usually the organization that has the most to gain from this change. This enables us to formulate ideas for requirements engineers for introducing creative changes. Our vision is close to the one described in [3, 9] but focuses more on the organizational issues, specifically the tension between stability and change. It is therefore also related to research in $\mathrm{RE}$ and organizational culture, e.g. [10].

In Section 2 we introduce creativity and some sources of resistance to change in organizations. In Section 3 we discuss creativity and RE. In Section 4 we list heuristics for conceptualizing factors that act against and in favor of change. In Section 5 we propose some techniques for promoting change in organizations.

\section{Creativity and Resistance to Change}

The traditional view on creativity is that at some point an individual or a group of individuals invent some novel change. This change creates a discontinuity with past practice and, durably changes subsequent events. Creativity requires divergent and convergent modes [8] of thinking. In the divergent (synthesis) modes, as many ideas as possible are generated, totally ignoring judgment. In the convergent or analytical modes, the relevance and feasibility of these ideas is examined. The creativity model described above focuses more on the phases that lead to the creative act and less on the way this act is accepted by an organization.

Csikszentmihalyi [2] proposes a systemic model for creativity. Csikszentmihalyi's model consists of the interactions of three sub-systems, domain, field, and person. A domain is that which is changed by the creative person. It consists of symbolic rules and procedures that we can refer to as norms [17]. It is these norms that the creative person proposes to change. The field is composed of a number of experts in the domain who act as guards to the domain. Changes to the norms of the domain must be approved 
by these experts. In other words, the creative person needs to convince the experts that he or she is proposing a valuable change to the current norms of the domain. We therefore ascribe a set of beliefs to the field. The norms of the domain are grounded in these beliefs. For the norms of the domain to change, the beliefs of the field need to change too. When the change is accepted by the field, the creative act is acknowledged and the domain and beliefs are permanently altered.

The role of the field is essential, for if it is too weak or doesn't exist at all, any idea can alter the domain whether it is a valuable idea or not. On the other hand, an overly conservative field will make change impossible so that no creativity will exist. This creates a tension between the need for change and the need for stability of the field.

To understand resistance to change, it is necessary to see that norms both enable and constrain change. On the one hand they enable some changes because without any norms, there's nothing to change. On the other hand they act against change since, by definition, a norm is an unchanged aspect. Hence, for Vickers [18] a norm is something with which a state of affairs can be judged. Without a relevant norm, an invention cannot be evaluated and either rejected or accepted. Change, therefore, is always expressed through comparison to a given norm or set of norms. Limiting this quest for change is the field's need for stability. Vickers, for example, argues that appreciative systems (which include norms and beliefs) can accept a limited rate of change.

\section{Creativity in RE}

Requirements engineers usually operate in organizational contexts to which they often need to bring a certain amount of change. Their domain is therefore the organization. Csikszentmihalyi [2] argues that creative techniques in organizations often amount to simply encouraging employees to come up with original ideas (through brainstorming techniques for example), ignoring the role of management in the acceptance and follow-up of these ideas.

It so happens that the field of experts judging whether the change is acceptable is usually more than just management. It can be either the formal organization, i.e. management, the informal organization, i.e. users and other stakeholders, or even people external to the organization such as clients and suppliers. There are many examples, e.g. [11, 13] of management sponsored projects that produced systems that were not used by their intended users. We will therefore refer to Csikszentmihalyi's field as adopters.
This clarifies the relationship between the requirements engineers and the stakeholders who adopt, or are supposed to adopt, the proposed change. As we have seen in the previous section, the adopters have a legitimate need for stability that counters the change proposed by the engineers. It is important for the engineers to take this need into account.

Living in a world of unchanging norms, however, is not a very exciting endeavor. There are many reasons for changing the state of affairs in organizations among which we can list the following: 1) no change ultimately leads to boredom, 2) dissatisfactions with the current state of affairs, 3) adaptation to external norm changes such as laws, regulations, culture, 4) the search for growth, especially in capitalistic economies, and finally, 5) the perceived threat to organizational survival, itself, serves as one of the most powerful motivations for innovation.

In summary, requirements engineers function as facilitators for helping adopters accept the changes proposed by creative agents. They also implement processes that help people in organizations become creative agents. They therefore need to understand their legitimate resistance to change.

Let's now take a fictitious example, based on a real life situation of a Swiss shopping mall parking lot, to illustrate the heuristics we describe in the next sections. In this example we discuss norms on how the parking lot can and should be managed. Understanding these norms is necessary to define the requirements for its management system.

In most malls in Switzerland, parking spaces are a scarce resource, especially in centers of town. Where parking lots are ample, they are not of much use for people other than mall customers because the mall is far from any otherwise useful place.

In one small Swiss village there is a mall that has a parking lot containing approximately 800 parking spots. The mall is very close (about $100 \mathrm{~m}$ ) to a train station that serves many small villages populated by relatively affluent residents. It is quite inconvenient to travel by public transportation to the station from the neighboring villages. Many of the residents of the surrounding villages work in a nearby city. The parking lot of the station is very small and during week days cannot accommodate all commuters' cars. Commuting to the city by car is expensive in lost time and parking fees. .

As is the norm in Switzerland, the parking lot of the mall is reserved for mall customers. People who attempt to park their car in the mall and take the train are subject to a fine imposed by a local judge.

People who misuse the parking lot have every chance of also being regular customers of the mall. If 
they receive a fine at the mall, they may take their valuable business somewhere else. The competition from other malls in the area is growing. During week days it seems that there are regularly a few hundred parking spots available, even in peak hours.

The mall probably already has a system in place to track parking lot usage and store license plates of offenders. The idea we submitted to the mall management was to allocate a few dozen parking spots for regular customers of the mall so that they can park their car in the mall's parking lot during weekdays.

Regular customers can be tracked through their use of a fidelity card which the mall already promotes. When a new car is identified, whose driver has "strayed" off from the mall, invite he or she to register with the preferred customer program. Undoubtedly, the requirements for a parking lot management system will be very different depending on the strategy taken by management with respect to this proposal.

\section{Heuristics for Understanding Resistance to Change in Organizations}

In this section we present a number of heuristics that can help requirements engineers to become more creative and/or become more effective in introducing new, presumably more effective, RE processes into their organization's design processes. We discuss the way each heuristic favors and prevents change.

\subsection{Homeostasis}

Homeostatic systems are systems that are capable of operating effectively within limits. These systems can tolerate and, continually adjust to, change so long as the change lies within an acceptably bounded region the homeostatic region. Adaptive feedback control systems such as temperature regulating systems are classic examples of homeostatic systems [5].

A homeostatic system acts against large positive or negative change in quite the same way. For the human body, for example, low or high blood pressure, too little or too much oxygen, too cold or too hot conditions are all threats to survival. The body will act against them attempting to maintain a bounded range of blood pressure, oxygen and temperature. In much the same way, an organization maintains a set of norms and attempts to correct for changes threatening to breach the organization's homeostatic region. Revenue that is too low, for example, is as threatening as revenue that is too high as compared with the habit of the organization.

Since any change is seen as a disturbance, it is very difficult for adopters to differentiate between threats and opportunities. This leads to the situation where resisting change is the safest bet. This is especially visible when an organization is successful. In this case calls for change are likely to be seen more as a threat than an opportunity. Bill Hunter sums it up nicely in [14], "When you go to a market leader with a disruptive technology most of the time they aren't interested."

Hence, a homeostatic system acts as an automatic pilot, correcting any deviation in the state of the system with the result that a norm is maintained over time.

Homeostasis can be a powerful engine of creativity because maintaining some norms may require much change in others. For example, maintaining the revenues of a company in the face of competition may mean regularly inventing new products and services.

Conversely, homeostasis acts as a barrier against change to the norm it is designed to maintain.

\section{Mall example:}

The Swiss norm of reserving parking lot use exclusively to mall customers provides a firm basis for maintenance. Multiple forces may oppose any attempt towards changing the purpose of the parking lot. The resistance to change can be due to: 1) management beliefs that this is not something to do, 2) the need to make special requirements for the IT system to accommodate such a change, 3) implementation costs, 4) regulatory constraints on the use of private parking lots, and a myriad of additional factors unknown to us.

A service such as the one we propose has its own homeostasis. Once established it has to be continued because customers will come to rely on it. If management wants to discontinue the service it risks alienating these customers. On the other hand, if the mall finances decline or if the threat of competition looms, the homeostasis of maintaining its revenue may help in accepting such a change as a way of maintaining existing customers and attracting new ones.

What will people who don't get allocated spots think of the service? What would the train company think of the move? Will it see it as a threat? What will government and other regulating bodies think of this trend? How would the competing malls react?

Is the proposed change an opportunity to improve the service rendered by the mall to its clients and fend off competitors or is it a threat which will cannibalize the use of the mall's parking lot so that in the long term the mall's clients will not find free parking spots? If the number of spots allocated to customers is not enough for all, will those who can't participate in this program be even less satisfied with the mall? 
The mall is quite successful right now. Why should it change? Maybe it isn't even aware that it is scaring some customers off.

\section{Recommendation:}

Identify which norms a proposed change is likely to disturb. Identify the mechanisms that act against change to these norms. Identify other norms that may be leveraged to implement a proposed change. Also, reflect on the usefulness of the proposed change and its consequences in the long term, e.g., maintaining the future situation created by the change.

\subsection{Internal worldview}

Norms and their maintenance are grounded in a set of beliefs shared by the adopters about the organization itself and its environment. Every organization has a specific set of beliefs that can be said to constitute its worldview. In this worldview the norms of the organization are considered normal. A typical example is reported by Baumard [1]. Baumard explains the 1986 Challenger accident through the gradual normalization and subsequent explicit acceptance of Oring damage in the shuttle boosters. It appears that this normalization made the damage seem acceptable. For Baumard in such cases, what appears to be normal and inconsequential for members of the organization may seem strange for external observers. Changing worldviews and the norms that depend on them is very difficult. Insiders have the same worldview as all the others whereas outsider views are brushed off or not even seen at all.

An internal worldview is common to all organizations, scientific disciplines and professions. It is needed for effective action and is most visible in the vocabulary shared by the members of the given community [2]. This vocabulary is a very potent barrier which excludes outsiders who cannot master the vocabulary. They are also easily identified based on their "poor" use of the vocabulary. These special vocabularies serve as a source of internal comfort as well as a source of hierarchical bilingualism.

Furthermore, if the homeostatic system is successful and the norms it maintains remain very stable for a long period of time, they then become invisible to the stakeholders. This is a direct corollary of perfect regulation, see [19]. The norm becomes apparent again only when a perturbation occurs, that disturbs the system sufficiently to be noticeable. An invisible norm is difficult to change not only because of homeostasis but also because it seems so obvious to the adopters that it is difficult to even make them aware of it.

\section{Mall example:}

The mall applies fines as a rule because it is the norm in Switzerland. No questioning is performed prior to applying this way of doing business. The norm is so ingrained that it just seems natural to keep the parking lot only for the use of the mall users and regularly fine people who park their car in the mall and leave it. It may seem obvious to the mall management that it is normal for the mall parking lot to be mostly empty most of the time while just $100 \mathrm{~m}$ away people struggle to find parking. Also it looks perfectly normal for them that these people may be their own customers.

\section{Recommendation:}

We need to go out of our way to learn the norms and worldview of the target organization without losing the creative thrust. We have found the concept of meta-questions to be especially useful for teasing out this form of tacit information. Freedman and Weinberg [4] define meta questions as "questions about questions." The requirements engineer would find such questions as the following to be potentially revealing:

- What critical information do you (the client, end user or other important user) know that I need to know but couldn't possibly yet know?

- What terms do you use that we either wouldn't understand or would understand to be different than your understanding?

- What have we forgotten to ask you that is important?

We have had very predictable experiences when shifting to these questions. The client or user will be instantly surprised, thinking we are surely joking, and then invariably pause to reflect for a moment before proceeding to provide surprisingly useful information information that would not likely have been obtained without such queries.

\subsection{Maintenance of identity}

The term homeostasis roughly means "remaining the same" [19]. The norms maintained by the homeostatic system form its identity for its observers [16]. Hence, it is not easy for an organization to change some of its norms. For example, a company that manufactures and sells computers doesn't easily change into a company that sells services. It is possible but not simple. When a change is proposed that may change a norm linked to the identity of the organization, management is faced with a critical decision to make.

\section{Mall example:}

Is the parking lot for the sole use of the mall? Can it be seen as a more general purpose service? What is the 
mission of the mall? The mall management can oppose the proposed change on the grounds that the mall is not a parking lot for train users. Also, management may feel uneasy about letting people park their car all day long in their (the mall) own parking lot. Considering that the use of the parking lot is reserved for regular mall customers may help sell the change.

\section{Recommendation:}

Identify the norms that are maintained by the organization and that are viewed as forming its identity by its stakeholders. It is then possible to decide whether to break this identity for a given set of stakeholders. Understanding the internal worldview of the organization can help understand the identity that it is trying to maintain. Understanding the worldview of the organization's stakeholders can help to understand the norms they expect from the organization.

\subsection{Management of resources}

The management of resources is a constant endeavor for an organization; most of the time it is about the distribution of scarce resources such as money, time, space, key people. Access to scarce resources is very highly regulated [15]. Conversely, sometime there are ample resources present. These often go unnoticed, similarly to the invisible norms we have seen above. Ample resources just like successful situations may not encourage creativity. For example, research into alternative fuel is difficult to justify when fuel is ample and inexpensive.

\section{Mall example:}

The norm of fining people who don't stay in the mall can be understood as a way of protecting a scarce resource (parking spots). However, it may be that the parking lot is so big that the spots are actually ample. This may be the case right now but management needs to look into the future too. They may want to keep this excess space in case they attract more customers in which case there won't be enough space for all.

\section{Recommendation:}

Try playing with ideas of changing ample to scarce resources and vice versa. Imagine what the consequences would be, what the world would look like, what stakeholders would be affected.

\section{Heuristics for Promoting Change}

We face especially difficult challenges in promoting the really big ideas - those famous quantum leaps or revolutionary discoveries. We know that members of stable organizations don't take well to revolutions [7]. As Schopenhauer put it, "Every truth passes through three stages before it is recognized. First it is ridiculed.
Second, it is violently opposed. Third, it is accepted as self-evident." In this Section, we discuss how change, big (revolutionary) as well as small (evolutionary), can be promoted in an organization.

We need to recognize that management always assumes risk whenever a new idea is approved and implemented or passed through them to higher levels in the company for ultimate approval and support. The greater the novelty of the idea, the greater this risk the risk of ridicule or of violent opposition. These risks added to the risk of unintended consequences, always present in the thinking of managers encountering new ways of doing things adds formidable pressure in favor of new idea rejection.

We therefore need to create situations for equalizing these risks. The playing field isn't level until management can believe they are assuming as much risk in rejecting the idea as accepting it. We have found a careful and credible case presenting not only the benefits of the new idea but also the risks of the same new idea to be effective in gaining and holding management's attention. When we take ourselves out of the advocacy position and, instead present convincing information on both sides of the idea, we put management in the position of making a more objective decision. This approach has the added advantage in offering us opportunity to refine the idea to more acceptable levels before offering it to management. As human beings we must realize that we often fall in love with our own ideas.

When a change is proposed which is so creative that there is no relevant norm with which it can be compared, it is likely to be simply discarded as folly. It can be said that ridicule is actually already a good reaction because it is a reaction. A really novel proposition may simply be ignored by the would-be adopters as if it had never happened. It is not that the adopters don't want to see it. They may simply be lacking the tools to sense it or understand it. However, the more far-fetched the proposal, the more it is likely to be creative. There's no escaping this paradox. The result is that small changes are more likely to be accepted than revolutionary ones. Small changes, after all are more likely to be within, or at least near the boundaries of, the organization's homeostatic region.

A pragmatic method that we have used productively draws its power from the concept of intellectual property. Those requirements engineers trying to convince their place of employment to adopt a new idea will, in almost every case, have signed an employment agreement containing, among other things, the company's right of first refusal on any idea the employee produces that is in anyway of value to the company. When we have exhausted all other rational means of gaining acceptance, then we 
formally submit a request for permission to release the idea to the company's most feared competitor. This creates a situation putting the organizational "powers that be" at risk by not better understanding the idea and by not exploring the idea's potential. Just imagine someone in the Xerox Palo Alto Research Center of the 1970's requesting a waiver of Xerox's intellectual property agreement concerning icon-driven click-anddrag screen navigation in order to give it (free-of-cost) to a Xerox competitor - real or imagined.

\section{Conclusions}

Creativity is an important aspect of RE but there are major legitimate mechanisms in place that limit creativity in order to maintain stability. In this paper we outlined a few of these mechanisms and proposed ways for dealing with them. This paper is a vision paper because we have limited our discourse to giving a mere outline. There are many more heuristics and much more we can say about each one of them than we can accommodate in a six page paper. The attentive reader might have realized that this page limitation in itself is a norm that limits and encourages creativity. It is our intent that this paper will serve as a beginning to deeper exploration into the dynamics of RE creativity and its role in advancing and accelerating the acceptance or $\mathrm{RE}$ research results into the mainstream practice of RE.

\section{$7 \quad$ References}

[1] Baumard, P., Tacit knowledge in Organizations. Sage, London, 1999.

[2] Csikszentmihalyi, M., Creativity: Flow and the psychology of discovery and invention, HarperPerennial, NY, NY, 1996.

[3] Dallman, S., Nguyen, L., Lamp, J. and Cybulski, J., "Contextual Factors Which Influence Creativity in Requirements Engineering," Proc. 13th European Conference on Information Systems, Regensburg, Germany, 2005.

[4] Freedman D.P. and G.M. Weinberg, Handbook of Wlkthroughs, Inspections and Technical Reviews, $3^{\text {rd }}$ ed., Scott, Foresman, NY, 1983

[5] Gause, D.C. and G. Rogers, "Cybernetics and Artificial Intelligence". in Cybernetics: Theory and Applications, R. Trappl, ed. Hemisphere, Hemisphere, N.Y., 1983

[6] Gause, D.C. and Weinberg, G. M., Exploring Requirements: Quality BEFORE Design, Dorset House, N.Y., 1989.

[7] Gause, D.C., "Comparative Evaluation in Requirements Engineering," Keynote, Workshop on Comparative Evaluation in Requirements Engineering, CERE'04, Kyoto, Japan, September 2004.

[8] Gause, D.C., "Requirements Driven Innovation: thinking the unthinkable, on the way to realizing the gee whiz",
Invited tutorial, 13th IEEE International Conference on Requirements Engineering, Paris, France, 2005

[9] Hoffmann, O., Cropley, D., Cropley, A., Nguyen, L. and Swatman, P., "Creativity, Requirements and Perspectives," Australasian Journal of Information Systems, Vol 13, No 1, pp. 159-175, 2005

[10] Kauppinen, M., Kujala, S., Aaltio, T. and Lehtola, L., "Introducing Requirements Engineering: How to Make a Cultural Change Happen in Practice," Proc. Tenth International IEEE Conference on Requirements Engineering, Essen, Germany, 2002.

[11] Kling, R., "What is Social Informatics and Why Does it Matter?” D-Lib Magazine, Vol. 5, No 1, January 1999.

[12] Maiden, N. and Robertson, S., "Integrating Creativity into Requirements Processes: Experiences with an Air Traffic Management System," Proc. 13th IEEE International Requirements Enginnering Conference, Paris, France, 2005.

[13] Markus, L.M. and Keil, M., "If We Built It, They Will come: Designing Information Systems that People Want to Use," Sloan Management Review, Summer 1994.

[14] MIT Technology Review October 2005.

[15] Regev, G. and Wegmann, A., "Defining Early IT system Requirements with Regulation Principles: the Lightswitch Approach" Proc. 12th IEEE International Requirements Engineering Conference, Kyoto, Japan, 2004.

[16] Regev, G. and Wegmann, A., "A Regulation-Based View on Business Process and Supporting System Flexibility," Proc. 6th BPMDS Workshop on Business Processes and Support Systems: Design for Flexibility BPMDS'05, Porto, Portugal, 2005.

[17] Regev, G. and Wegmann, A., "Where do Goals Come From: the Underlying Principles of Goal-Oriented Requirements Engineering" Proc. 13th IEEE International Requirements Engineering Conference, Paris, France, 2005.

[18] Vickers, Sir G., Policymaking, Communication, and Social Learning, Adams, G.B., Forester, J. and Catron, B.L., ed. Transaction Books. New Brunswick NJ, 1987.

[19] Weinberg, G. M. and Weinberg, D., General Principles of Systems Design, Dorset House. New York, 1988. 